\title{
Correction to: Cosmetics and Lasers
}

Caitlin Farmer, Matteo Lopiccolo and Alison T. Boucher

\section{Correction to:}

\section{Chapter "Cosmetics and Lasers" in:}

\section{H. W. Lim et al. (eds.), Practical Guide to Dermatology,} https://doi.org/10.1007/978-3-030-18015-7_5

The original version of this chapter was inadvertently published with incorrect authorship in the opening page of Chapter "Cosmetics and Lasers". The first author's name has been changed to "Caitlin Farmer". The erratum chapter has been updated with the change. 